\title{
COURSE ALLOCATION AMONG LECTURERS USING PYTHON
}

\author{
LAI ANN NA AND MOHAMED SAIFULLAH HUSSIN*
}

Faculty of Ocean Engineering Technology and Informatics, Universiti Malaysia Terengganu, 21030 Kuala Nerus, Terengganu, Malaysia.

*Corresponding author: saifullah@umt.edu.my

http://doi.org/10.46754/umtjur.2021.10.014

\begin{abstract}
Course allocation among lecturers describes the process of allotting a set of courses to a number of lecturers. The administrators who are responsible in the allotment of courses to lecturers at least once a year are supposed to assign the most suitable lecturer to teach the courses in an efficient and effective way. However, the process of course allocation among lecturers is being done manually in most of the educational institutions through a trial-and-error manner and the lecturers' years of teaching experience was not being considered during the allocation causing imprecision of the allocation made. Therefore, a random allocation of courses to lecturers using Microsoft Excel was done and the objective function of the solution obtained through the random allocation is compared to the objective functions of exact solutions obtained using OpenSolver and Python. The purpose of using Python is to automate the allocation of courses to lecturers in which a lecturer's years of teaching experience is being optimized even if there is occurrence of data changes. Besides that, the computational time used in obtaining the solutions using the three mentioned approaches are compared to show the difference in terms of efficiency and effectiveness of the allocation made. Python proved to be the most efficient and effective approach as compared to the other two approaches used for this course allocation problem as Python requires the least time and effort to obtain the optimal combination of lecturers and courses based on lecturers' years of experience.
\end{abstract}

Keywords: Python, course allocation, lecturers, years of experience, optimization.

\section{Introduction}

A university consists of multiple faculties or schools where faculties, in turn are often made up of several departments. Departments offer courses that include core courses and elective courses to students to meet the academic requirements of undergraduate and post-graduate students. The academic performance of students in a university depends on how well the student is being taught and also the capability of student coping with the course (Emeka, 2018). Lecturers who work at postsecondary institutions like universities are the biggest guide and also the most influential factor contributing to student achievement. Therefore, course allocation among lecturers is an important aspect to be focused on, and this can be seen from works that have been done previously (Amuji et al., 2017; Badri, 1996; Gunawan \& Ng, 2011 \& Shohaimay et al., 2016).
Course allocation involves the assignment of a certain number of lecturers to teach a set of courses offered. The administrators who are responsible in course allocation will need to allocate the courses to lecturers at least once a year due to the occurrence of changes in the number of lecturers, courses, classes and students. For instance, the administrators need to administer the allocation of courses again when any lecturer is not available due to maternity leave or retirement, or when courses are cancelled or developed due to low or high demand. Since the process of allocating teaching load that involves allocation of courses among lecturers is being done manually in most of the educational institutions through a laborious trial-and-error approach (Shohaimay et al., 2016), therefore it will be time-consuming, noneffective and has bias tendency (Emeka, 2018) due to unequal teaching load. 
Therefore, the objectives of this study are to identify the most effective and efficient method that can be used by administrators to automatically allocate courses to lecturers and to optimize the allocation of courses to lecturers according to their years of experience in teaching the courses using Python. The approaches are necessary to obtain the optimal combination between lecturers and courses within a short period of time so that the lecturers have more priority to teach the courses that they are experts in. This helps to increase the students' understanding as the courses will be taught by experienced lecturers (Helen, 2013). In this study, the lecturers and courses involved are from the Mathematics Programme which consists of Applied Mathematics and Financial Mathematics from the Faculty of Ocean Engineering Technology and Informatics, Universiti Malaysia Terengganu.

\section{Methods}

The methods for this study are divided into data collection, random allocation of courses among lecturers using Microsoft Excel, allocation of courses among lecturers depending on the lecturers' years of teaching experience using OpenSolver and allocation of courses among lecturers depending on years of teaching experience using Python. The objective of this allocation is to maximize the years of teaching experience of lecturers in teaching the courses. This is based on the assumption that the longer a teacher teaches a certain subject, the better he gets in delivering that subject to his students. The solutions' objective function and computational time obtained from random allocation and allocation of courses among lecturers using OpenSolver and Python are then compared to show the difference in terms of efficiency and effectiveness of the allocation made.

There are some rules for this study on the allocation of courses among lecturers. The rules include:
1. The allocation of courses among lecturers must satisfy the minimum and maximum number of courses to be allocated to the lecturers.

2. The number of lecturers allocated to a course must be equal to the number of classes of that course. The number of classes is determined every semester by the Mathematics department.

3. Each lecturer cannot be allocated to the same course again if he or she has been allocated once so that the occurrence of a lecturer teaching all the classes for the same course can be avoided.

\section{Data Collection}

The data such as the total number of lecturers, total number of courses and total number of classes for each course, and also the minimum number of courses to be taught by each lecturer are obtained by interviewing the Head of Department (HOD) of Mathematics Programme in the Faculty of Ocean Engineering Technology and Informatics, Universiti Malaysia Terengganu. Furthermore, the data on lecturers' years of experience in teaching the courses offered in the Mathematics Programme are collected using online questionnaire via Google Form.

There are 25 core courses with 63 classes, 11 elective courses with 11 classes and eight service courses with 14 classes. A total of 28 lecturers are involved in this allocation. The minimum number of courses to be taught by the lecturers in a year is three courses per person excluding the lecturers who have administrative posts. The lecturers who are involved in administrative jobs are required to be allocated to at least two courses per person in a year. The maximum number of courses each lecturer can be allocated in a year is not being set by the department, therefore the addition of a course for each lecturer from his or her minimum number of courses to be allocated would be considered as the maximum number of courses that can be allocated. For instance, a lecturer who teaches at least three courses per year would have a maximum of four courses that he or she can teach in a year. 


\section{Random Allocation of Courses among Lecturers Using Microsoft Excel}

Random allocation is a fair allocation without considering any prior allocation factors that involved, in which it ensures that each course has the same opportunity to be assigned to any lecturer. Random allocation is done by using Microsoft Excel. There is a list of 44 courses with 88 classes to be assigned to 28 lecturers. RAND function is used to obtain a random number for each class. RANDgenerate numbers between 0 and 1 .

Since RAND is a volatile function, therefore it will recalculate every time the worksheet changed. To avoid the changing of random numbers generated, the formula is converted to values by using paste special. Next, the RANK function is used to rank each class according to the random numbers generated. The rank is then divided by the number of classes with different courses each lecturer will be assigned to. The values obtained through the division between rank and the number of classes with different courses each lecturer need to be assigned are then round up using CEILING with multiple of 1 . The values obtained will be between 1 to 28. Each lecturer would probably be assigned with two, three or four classes of different courses depending on lecturer's minimum and maximum number of courses per year.

\section{Course Allocation among Lecturers Using OpenSolver}

Course allocation among lecturers in this study is a problem of zero-one integer programming (Hillier \& Lieberman, 2010 \& Joshi \& Moudgalya, 2004) in which each variable can only take the value of 1 (yes) or 0 (no). The allocation of courses among lecturers is a maximization problem in which it maximizes the teaching experience of lecturers. The mathematical model to solve the problem of courses allocation among lecturers using OpenSolver is:
Maximize $\mathrm{Z}=\sum_{i \in I} \sum_{j \in J} c_{i j} x_{i j}$

Subject to: $\quad \sum_{i \in I} x_{i j}=b_{i}$, for $j \in J$

$$
\begin{gathered}
d_{j}^{\text {min }} \leq \sum_{j \in J} x_{i j} \leq d_{j}^{\text {max }} \text {, for } i \in I \\
j_{i} \leq b_{i}
\end{gathered}
$$

All variables must be 0 or 1 .

Where $I$ is all the courses offered, $i$

$J$ is all the lecturers involved, $j$

$x_{i j}$ is the decision variable,

$b_{i}$ is the number of classes for course $i$,

$c_{i j}$ is the years of experience of lecturer in teaching course $i$,

$d_{j}^{\min }$ is the minimum number of courses to be allocated to lecturer $j$,

$d_{j}^{\max }$ is the maximum number of courses to be allocated to lecturer $j$,

The decision variable is:

$x_{i j}=\left\{\begin{array}{l}1 \text { if course } i \text { is allocated to lecturer } j \\ 0, \text { other }\end{array}\right.$

The objective function of this model is the sum of the decision variable $x_{i j}$ and years of experience $c_{i j}$ for all courses $i$ and lecturers $j$. This zero-one integer programming problem of allocation of courses among lecturers is then solved by using OpenSolver where it is a free, open source software that consists of COINOR CBC optimization engine which can help to solve Linear and Integer problems regardless of the size of the problem.

\section{Course Allocation among Lecturers Using Python}

Python programming language is a high-level programming language that is powerful to reflect people's way of thinking and their way of code implementation (Bogdanchikov et al., 2013). Besides that, Python programming language is easier to read and also to write compared to other programming languages because it reduces the usage of extra keywords needed to write syntactically an error-free programme. 
Besides that, Python has a lot of libraries. One of the libraries that is free, open and has the capabilities in calling GLPK, COIN CLP/ CBC, CPLEX and GUROBI to solve LP problems apart from developing MPS or LP files is called PuLP. PuLP and another free open-source library written in Python called Pandas has the capabilities of manipulating, analyzing and cleaning the data that will be used for this course allocation problem.

The data of the lecturers' years of teaching experience for each course, the minimum and maximum number of courses each lecturer need to be assigned to and the number of classes of each course are saved in an Excel commaseparated values (CSV) file. The Excel CSV file is imported into Python using Pandas and the process of slicing is carried out to select and save the sets of DataFrame needed as variables. The aim of this allocation problem is to maximize lecturers' years of teaching experience, therefore LpMaximize is used. Besides that, LpBinary is used to ensure all decision variables are binary. Only two symbols, "0" and "1" are used. The objective function and the constraints of course allocation, among lecturers, are then built up. Finally, this allocation problem is solved using model.solve and pulp.LpStatus [model.status].

\section{Results and Discussion}

The solutions obtained for course allocation among lecturers using MS Excel, OpenSolver and Python are shown in Table 1.

Table 1: Allocation of courses among lecturers using MS Excel, OpenSolver and Python

\begin{tabular}{|c|c|c|c|c|}
\hline No. & Lecturer & $\begin{array}{c}\text { Random Solution-MS } \\
\text { Excel }\end{array}$ & $\begin{array}{l}\text { Exact Solution- } \\
\text { OpenSolver }\end{array}$ & Exact Solution-Python \\
\hline \multirow[t]{3}{*}{1} & Prof. Dr. Lazim & Real Analysis & Algebra & Algebra \\
\hline & & $\begin{array}{l}\text { Mathematical Fluid } \\
\text { Mechanics }\end{array}$ & Statistics & Statistics \\
\hline & & Engineering Statistics & Biostatistics & Biostatistics \\
\hline \multirow[t]{3}{*}{2} & Prof. Dr. Fatah & Linear Algebra & Calculus & Calculus \\
\hline & & Biostatistics & Topology & Topology \\
\hline & & & Fuzzy Set Theory & Fuzzy Set Theory \\
\hline \multirow[t]{4}{*}{3} & Dr. Safiih & Algebra & Statistics & Statistics \\
\hline & & $\begin{array}{l}\text { Computer Programming } \\
\text { Language }\end{array}$ & Advanced Statistics & Financial Econometrics \\
\hline & & Modern Algebra & Introduction to Statistics & Advanced Statistics \\
\hline & & Optimization & & Introduction to Statistics \\
\hline \multirow[t]{3}{*}{4} & Dr. Norizan & Calculus & Numerical Analysis & Advanced Calculus \\
\hline & & Advanced Statistics & Financial Forecasting & Financial Forecasting \\
\hline & & Linear Programing & Statistics for Chemistry & Statistics for Chemistry \\
\hline \multirow[t]{3}{*}{5} & Dr. Roslan & Stochastic Modelling & Real Analysis & Real Analysis \\
\hline & & Operational Research & Complex Variable Calculus & $\begin{array}{l}\text { Complex Variable } \\
\text { Calculus }\end{array}$ \\
\hline & & Engineering Mathematics & Graph Theory & Graph Theory \\
\hline
\end{tabular}




\begin{tabular}{|c|c|c|c|c|}
\hline \multirow[t]{3}{*}{6} & Dr. Zabidin & Statistics & Modern Algebra & Modern Algebra \\
\hline & & Graph Theory & Real Analysis & Real Analysis \\
\hline & & Biostatistics & Functional Analysis & Functional Analysis \\
\hline \multirow[t]{3}{*}{7} & Dr. Termimi & Advanced Calculus & Algebra & Algebra \\
\hline & & Numerical Analysis & Linear Algebra & Linear Algebra \\
\hline & & Real Analysis & Geometric Modelling & Advanced Statistics \\
\hline \multirow[t]{3}{*}{8} & Dr. Auni & Numerical Analysis & Algebra & Differential Equation \\
\hline & & Statistics & Differential Equation & Algebra \\
\hline & & Vector Calculus & $\begin{array}{l}\text { Partial Differential } \\
\text { Equation }\end{array}$ & $\begin{array}{l}\text { Partial Differential } \\
\text { Equation }\end{array}$ \\
\hline \multirow[t]{3}{*}{9} & Dr. Azwani & Investment Mathematics & Calculus & Calculus \\
\hline & & Optimization & Advanced Calculus & Advanced Calculus \\
\hline & & $\begin{array}{l}\text { Advanced Numerical } \\
\text { Analysis }\end{array}$ & Numerical Analysis & Numerical Analysis \\
\hline \multirow[t]{3}{*}{10} & Dr. Binyamin & Algebra & Linear Algebra & Linear Algebra \\
\hline & & Differential Equation & Optimization & Optimization \\
\hline & & Statistics for Chemistry & Financial Optimization & Financial Optimization \\
\hline \multirow[t]{3}{*}{11} & Dr. Che Imran & Advanced Calculus & Investment Mathematics & Investment Mathematics \\
\hline & & Geometric Modelling & $\begin{array}{l}\text { Mathematical Theory in } \\
\text { Insurance }\end{array}$ & $\begin{array}{l}\text { Mathematical Theory in } \\
\text { Insurance }\end{array}$ \\
\hline & & Statistics for Chemistry & Financial Risk Analysis & Financial Risk Analysis \\
\hline \multirow[t]{3}{*}{12} & Dr. Chee & Statistics & Statistics & Statistics \\
\hline & & Financial Econometric & Biostatistics & Biostatistics \\
\hline & & Partial Differential Equation & Statistics for Chemistry & Statistics for Chemistry \\
\hline \multirow[t]{4}{*}{13} & Dr. Fatimah & Calculus & Advanced Calculus & Advanced Calculus \\
\hline & & $\begin{array}{l}\text { Computer Programming } \\
\text { Language }\end{array}$ & Differential Equation & Differential Equation \\
\hline & & Engineering Mathematics & Mathematical Methods & Mathematical Methods \\
\hline & & & Engineering Mathematics & $\begin{array}{l}\text { Engineering } \\
\text { Mathematics }\end{array}$ \\
\hline \multirow[t]{3}{*}{14} & Dr. Hanafi & Advanced Statistics & Statistics & Statistics \\
\hline & & $\begin{array}{l}\text { Probability Theory in } \\
\text { Finance }\end{array}$ & Advanced Statistics & Advanced Statistics \\
\hline & & Numerical Analysis & Stochastic Modelling & Stochastic Modelling \\
\hline \multirow[t]{3}{*}{15} & Dr. Hassilah & Calculus & $\begin{array}{l}\text { Probability Theory in } \\
\text { Finance }\end{array}$ & $\begin{array}{l}\text { Probability Theory in } \\
\text { Finance }\end{array}$ \\
\hline & & Linear Algebra & Investment Mathematics & Investment Mathematics \\
\hline & & Biostatistics & $\begin{array}{l}\text { Introduction to Stochastic } \\
\text { Differential Equation }\end{array}$ & $\begin{array}{l}\text { Introduction to } \\
\text { Stochastic Differential } \\
\text { Equation }\end{array}$ \\
\hline
\end{tabular}




\begin{tabular}{|c|c|c|c|c|}
\hline \multirow[t]{3}{*}{16} & Dr. Ilyani & Computer Programming & Linear Algebra & Linear Algebra \\
\hline & & Linear Algebra & Differential Equation & Differential Equation \\
\hline & & Mathematics for Chemistry & $\begin{array}{l}\text { Mathematics Fluid } \\
\text { Mechanics }\end{array}$ & $\begin{array}{l}\text { Mathematics Fluid } \\
\text { Mechanics }\end{array}$ \\
\hline \multirow[t]{3}{*}{17} & Dr. Maharani & Linear Algebra & Advanced Statistics & Stochastic Modelling \\
\hline & & Mathematical Methods & Financial Derivatives & $\begin{array}{l}\text { Advanced Numerical } \\
\text { Analysis }\end{array}$ \\
\hline & & Financial Derivatives & $\begin{array}{l}\text { Advanced Numerical } \\
\text { Analysis }\end{array}$ & $\begin{array}{l}\text { Numerical Modelling in } \\
\text { Finance }\end{array}$ \\
\hline \multirow[t]{3}{*}{18} & $\begin{array}{l}\text { Dr. Mohd. } \\
\text { Nazri }\end{array}$ & $\begin{array}{l}\text { Computer Programming } \\
\text { Language }\end{array}$ & Real Analysis & Linear Algebra \\
\hline & & $\begin{array}{l}\text { Introduction to Statistics } \\
\text { Differential Equation }\end{array}$ & Financial Econometrics & Real Analysis \\
\hline & & Introduction to Statistics & Mathematics & Mathematics \\
\hline \multirow[t]{4}{*}{19} & Dr. Saifullah & Calculus & $\begin{array}{l}\text { Computer Programming } \\
\text { Language }\end{array}$ & $\begin{array}{l}\text { Computer Programming } \\
\text { Language }\end{array}$ \\
\hline & & Differential Equation & Linear Programming & Linear Programming \\
\hline & & $\begin{array}{l}\text { Mathematical Theory in } \\
\text { Insurance }\end{array}$ & Operational Research & Operational Research \\
\hline & & & Optimization & Optimization \\
\hline \multirow[t]{4}{*}{20} & Dr. Aidya & Advanced Statistics & Calculus & Calculus \\
\hline & & Operational Research & Linear Programming & Linear Programming \\
\hline & & $\begin{array}{l}\text { Numerical Modelling in } \\
\text { Finance }\end{array}$ & Operational Research & Operational Research \\
\hline & & & Mathematical for Chemistry & $\begin{array}{l}\text { Mathematical for } \\
\text { Chemistry }\end{array}$ \\
\hline \multirow[t]{4}{*}{21} & Dr. Fadhilah & Linear Programming & Linear Programming & Linear Programming \\
\hline & & Advanced Calculus & Operational Research & Operational Research \\
\hline & & Optimization & Optimization & Optimization \\
\hline & & Mathematics & & \\
\hline \multirow[t]{3}{*}{22} & Dr. Ruwaidiah & Advanced Calculus & Advanced Calculus & Advanced Calculus \\
\hline & & Real Analysis & Vector Calculus & Vector Calculus \\
\hline & & Functional Analysis & $\begin{array}{l}\text { Introduction to Stochastic } \\
\text { Differential Equation }\end{array}$ & $\begin{array}{l}\text { Introduction to } \\
\text { Stochastic Differential } \\
\text { Equation }\end{array}$ \\
\hline \multirow[t]{3}{*}{23} & Dr. Shalela & Algebra & Numerical Analysis & Numerical Analysis \\
\hline & & $\begin{array}{l}\text { Probability Theory in } \\
\text { Finance }\end{array}$ & Introduction to Calculus & Introduction to Calculus \\
\hline & & Topology & Mathematics for Chemistry & $\begin{array}{l}\text { Mathematics for } \\
\text { Chemistry }\end{array}$ \\
\hline
\end{tabular}




\begin{tabular}{|c|c|c|c|c|}
\hline \multirow[t]{3}{*}{24} & \multirow[t]{3}{*}{ Dr. Syerrina } & Advance Statistics & $\begin{array}{l}\text { Computer Programming } \\
\text { Language }\end{array}$ & Advanced Statistics \\
\hline & & Stochastic Modelling & Advanced Calculus & Numerical Analysis \\
\hline & & Operational Research & Advanced Statistics & Financial Derivatives \\
\hline \multirow[t]{4}{*}{25} & \multirow[t]{4}{*}{ Dr. Ummu } & Differential Equation & Calculus & Calculus \\
\hline & & $\begin{array}{l}\text { Introduction to Stochastic } \\
\text { Differential Equation }\end{array}$ & $\begin{array}{l}\text { Computer Programming } \\
\text { Language }\end{array}$ & $\begin{array}{l}\text { Computer Programming } \\
\text { Language }\end{array}$ \\
\hline & & Financial Optimization & Linear Algebra & $\begin{array}{l}\text { Probability Theory in } \\
\text { Finance }\end{array}$ \\
\hline & & & $\begin{array}{l}\text { Probability Theory in } \\
\text { Finance }\end{array}$ & \\
\hline \multirow[t]{3}{*}{26} & \multirow[t]{3}{*}{ Dr. Baini } & Algebra & Algebra & $\begin{array}{l}\text { Computer Programming } \\
\text { Language }\end{array}$ \\
\hline & & Statistics & $\begin{array}{l}\text { Numerical Modelling in } \\
\text { Finance }\end{array}$ & Financial Derivatives \\
\hline & & Financial Forecasting & Biostatistics & Biostatistics \\
\hline \multirow[t]{3}{*}{27} & \multirow[t]{3}{*}{ Pn. Azlida } & Linear Programming & $\begin{array}{l}\text { Computer Programming } \\
\text { Language }\end{array}$ & Algebra \\
\hline & & Investment Mathematics & Stochastic Modelling & $\begin{array}{l}\text { Computer Programming } \\
\text { Language }\end{array}$ \\
\hline & & Fuzzy Set Theory & Financial Derivatives & Geometric Modelling \\
\hline \multirow[t]{4}{*}{28} & \multirow[t]{4}{*}{$\begin{array}{l}\text { Pn. Siti } \\
\text { Madhihah }\end{array}$} & Financial Derivatives & Engineering Mathematics & $\begin{array}{l}\text { Engineering } \\
\text { Mathematics }\end{array}$ \\
\hline & & Introduction to Calculus & Engineering Statistics & Engineering Statistics \\
\hline & & Biostatistics & Biostatistics & Biostatistics \\
\hline & & Mathematics for Chemistry & & \\
\hline
\end{tabular}

From the results, the comparison of the objective function and the computational time in obtaining the solution for course allocation among lecturers using three different methods is shown in Table 2. The methods include random allocation, allocation of courses among lecturers using OpenSolver and allocation of courses using Python.

Table 2: Comparison of objective function and computational time

\begin{tabular}{cccc}
\hline \multicolumn{1}{c}{ Methods } & Random & OpenSolver & Python \\
\hline Objective Function & 64 & 419 & 419 \\
Computational Time & 1 minute 31 second & 4 minute 19 second & 9 second \\
\hline
\end{tabular}

From Table 2, the objective function of the solution obtained through random allocation is the least which is 64 whereas the objective function obtained using OpenSolver and Python is the most which is 419 . This shows that the problem of course allocation among lecturers can be solved in the most effective way using OpenSolver and Python because the solutions obtained have successfully produced a desired or intended result which is to maximize 
lecturers' years of experience in teaching the courses. Conversely, random allocation is not an effective approach to solve course allocation among lecturers because the allocation made did not assign the correct courses to the most suitable lecturer.

The computational time required to obtain the solution for course allocation problem is the least when the allocation is made using Python (9 seconds) followed by random allocation (1 minute and 31 seconds) and finally using OpenSolver (4 minutes and 19 seconds). Python proved to be the most efficient way to solve the problem of course allocation among lecturers because it performs the fastest compared to random allocation and allocation of courses among lecturers using OpenSolver.

The computational time is actually dependent on the size of the problem. If the size of the problem is small, then the computational time required is less and vice versa. Since the allocation made using Python requires the least computational time followed by random allocation and lastly OpenSolver, this sequence of efficiency level will remain the same regardless of the occurrence of data changes. For instance, a course is removed or an addition of new lecturer will not change the fact that Python is the most efficient approach to perform the allocation of courses as it can automatically read the changes of data in the CSV file into Python.

Since the objective of this study is to identify the most effective and efficient method that can help administrators to allocate courses to lecturers automatically where the lecturers' years of experience are optimized, therefore both aspects which include the effectiveness and efficiency of the allocation made are taken into account. Course allocation among lecturers using Python is the most effective and efficient approach to assign the most suitable lecturers who are experts to teach the courses based on their years of experience in teaching the courses.

\section{Conclusion}

In this study, one of the objectives is to identify the most effective and efficient method that can help administrators automatically allocate courses to lecturers. Therefore, three methods are used to solve the problem of course allocation among lecturers of the Mathematics Programme in the Faculty of Ocean Engineering Technology and Informatics, Universiti Malaysia Terengganu. The methods consist of random allocation using MS Excel, allocation of courses among lecturers using OpenSolver and allocation of courses among lecturers using Python. Both process of allocating courses to lecturers using OpenSolver and Python is based on LP approach where the solutions obtained are exact solutions. The objective functions and computational time needed for the process of allocating courses to lecturers through the three mentioned approaches are also being compared. It is concluded that Python is the most effective and efficient method for administrators to automatically allocate courses to lecturers. The reason is that Python requires the least time to obtain the desired solution.

Moreover, this study is also aimed to optimize the allocation of courses among lecturers by maximizing lecturers' years of teaching experience. An online questionnaire was conducted to obtain the years of teaching experience of each lecturer for each course. All solutions obtained through these three approaches are feasible where all constraints are satisfied. The constraints include the minimum and maximum number of courses to be assigned to each lecturer. Besides that, the number of lecturers assigned to each course is ensured that it is identical to the number classes required for that particular course. The number of classes for each course is determined by the respective departments at UMT, and in this case, the Mathematics department. Finally, each lecturer 
is not assigned to the same course again when he or she has been assigned once. The results obtained showed that the objective function of the allocation made using OpenSolver and Python is the most which is 419 . This indicates that the courses would be assigned and taught by lecturers that have the most experience.

Although the objective function of the solution obtained using OpenSolver and Python is the maximum, the computational time of course allocation using OpenSolver is longer compared to Python. Therefore, Python would be recommended to administrators to perform the process of course allocation. This is because Python allows easier reallocation whenever there are changes in the data such as the number of lecturers available and the number of courses offered.

Despite the benefit of using Python over random allocation using MS Excel or OpenSolver, there is still a drawback when using it. When one needs to develop a new programme to solve a specific problem, writing the initial Python code will take the most time compared to other approaches. However, if the code written needs to be re-used again, then this can be done within a shorter time frame.

For future studies one can improve the current model by including more factors in the model, such as the teaching performance, research interest, or even considering students' preferences.

\section{References}

Amuji, H. O., Ugwuanyim, G. U., Ogbonna, C. J., Iwu, H. C. \& Okechukwu, B. N. (2017). The usefulness of dynamic programming in course allocation in the Nigerian Universities. Open Journal of Optimization. 176-186.
Badri, M. A. (1996). A two-stage multiobjective scheduling model for [faculty-coursetime] assignment, European Journal of Operational Research. 16-28.

Bogdanchikov, A., Zhaparov, M., \& Suliyev, R. (2013). Python to learn programming. Journal of Physics: Conference series 423 (2013) 012027. doi: 10.1088/17426596/423/1/012027.

Emeka, A. G. (2018). An algorithm for efficient allocation of courses to lecturers for effective teaching. International Journal of Engineering Science Invention (IJESI), 7(9): 68-74.

Gunawan, A., \& Ng, K. M. (2011). Solving the teacher assignment problem by two metaheuristics. International Journal of Information and Management Sciences. 7386.

Helen, F. L. (2013). Why experienced teachers are important-and what can be done to develop them. Scholars Strategy Network. Retrieved from https://scholars.org/ contribution/why-experienced-teachersare-important-and-what-can-be-donedevelop-them.

Hillier, F. S., \& Lieberman, G. J. (2010). Introduction to operational research. Boston: McGraw-Hill.

Joshi, M. C., \& Moudgalya, K. M. (2004). Optimization: theory and practice. United Kingdom, UK: Alpha Science International Ltd.

Shohaimay, F., Dasman, A., \& Suparlan, A. (2016). Teaching load allocation using linear programming. Business Management and Computing Research Colloquium (BMCRC). 
